19 Revue d'histoire du XIXe siècle

Société d'histoire de la révolution de 1848 et des

révolutions du XIXe siècle

$39 \mid 2009$

Le monde de l'imprimé: des territoires aux acteurs -

Education et politique - Histoires politiques

\title{
Raúl A. RAMOS, Beyond the Alamo: Forging Mexican Ethnicity in San Antonio, 1821-1861
}

Chapel Hill (N.C.), University of North Carolina Press, 2008, 297 p. ISBN :

978-0-80780-3207-3. 35 dollars.

Tangi Villerbua elit.

\section{(2) OpenEdition}

Journals

Édition électronique

URL : http://journals.openedition.org/rh19/3975

DOI : 10.4000/rh19.3975

ISSN : 1777-5329

Éditeur

La Société de 1848

Édition imprimée

Date de publication : 10 décembre 2009

Pagination : 192-193

ISSN : 1265-1354

Référence électronique

Tangi Villerbua elit., « Raúl A. RAMOS, Beyond the Alamo: Forging Mexican Ethnicity in San Antonio,

1821-1861 », Revue d'histoire du XIXe siècle [En ligne], 39 | 2009, mis en ligne le 26 mars 2010, consulté

le 22 septembre 2020. URL : http://journals.openedition.org/rh19/3975 ; DOI : https://doi.org/

$10.4000 /$ rh19.3975

Ce document a été généré automatiquement le 22 septembre 2020.

Tous droits réservés 


\section{Raúl A. RAMOS, Beyond the Alamo: Forging Mexican Ethnicity in San Antonio, 1821-1861}

Chapel Hill (N.C.), University of North Carolina Press, 2008, 297 p. ISBN :

978-0-80780-3207-3. 35 dollars.

\section{Tangi Villerbua elit.}

1 Le Texas espagnol et mexicain, les Tejanos, et plus encore les résidants de San Antonio, ont la chance de bénéficier d'un regard particulièrement soutenu de la part des historiens américains. Il est peu d'autre exemple dans l'histoire de l'Ouest américain d'une ville qui dépassait avec peine les 1500 âmes et qui suscite encore une telle abondance de travaux. Au point que l'on peut légitimement se demander en quoi un ouvrage supplémentaire, dont le titre annonce de surcroît des problématiques déjà maintes fois abordées, autour de l'ethnicité notamment, peut apporter du neuf.

2 En effet, Raúl A. Ramos revisite ici les grands épisodes de l'histoire du premier XIX ${ }^{\mathrm{e}}$ siècle texan. Au fil de cette histoire essentiellement politique, il dessine les enjeux identitaires auxquels doivent faire face les Tejanos. Le Texas, qui longtemps n'existe pas en tant qu'entité administrative autonome, est en effet durant des décennies une zone de troubles. Sous souveraineté espagnole d'abord, parce qu'en 1811 puis 1813 San Antonio est secouée par des insurrections indépendantistes mexicaines, les marges nord de la Nouvelle-Espagne n'échappant pas aux soubresauts continentaux. Sous souveraineté mexicaine ensuite, à partir de 1821, à la fois parce que le Texas - et le Coahuila auquel il est rattaché - participe aux débats parfois violents sur la forme que doit prendre le nouvel État national mexicain et parce que l'arrivée massive de colons anglo-américains - d'abord invités par les autorités avant qu'elles ne tentent de freiner le mouvement - déséquilibre le territoire et mène à des tensions qui peuvent déboucher sur du sécessionnisme, comme lors de la proclamation de la très éphémère République de Fredonia en 1826 ; lors de la révolte texane de 1836, marquée par les batailles d'Alamo, les sièges de San Antonio et l'indépendance d'un Texas désormais à majorité anglo-américaine ; lors des deux réoccupations de San Antonio par les troupes 
mexicaines au printemps et à l'automne 1842 ; quand le Texas est annexé par les ÉtatsUnis en 1845 et qu'est déclenchée la Guerre du Mexique (1846-1848); et enfin lorsque le nouvel État décide en 1861 de rejoindre la Confédération sudiste.

3 Une fois les acteurs présentés et leurs caractéristiques essentielles dessinées - une société très ordonnée fondée sur le prestige et l'honneur pour les Tejanos; un monde indien divisé entre Comanches qui ont passé un accord avec le Mexique, Indiens des missions, tribus venues récemment des États-Unis en quête de nouvelles terres et nomades, le tout formant avec les Tejanos «un monde plein de problèmes et de possibilités » (p.79); migrants américains essentiellement sudistes et pouvant rencontrer les élites tejanas sur la base d'une civilisation de l'honneur avant que l'avantage démographique ne change la donne - il s'agit pour l'auteur de passer au crible les changements apportés à la définition identitaire des seuls Tejanos au fil de ces années troublées. L'argumentaire s'appuie sur les meilleures sources disponibles et sur les travaux les plus récents, qui abondent sur le sujet. Le genre trouve donc sa place, dans l'optique désormais classique de l'analyse des stratégies matrimoniales croisées des vainqueurs anglos et des vaincus tejanos de la conquête ${ }^{1}$, de même qu'une réflexion sur la stratification sociale mais sans que soit jamais totalement éclairci le comportement des couches populaires tejanas tant l'accent est mis en permanence sur les grandes familles, celles qui ont laissé des traces archivistiques et qui se sont alliées aux nouveau venus américains. De même l'apport fondamental du travail d'Andres Reséndez, à savoir la prise en compte dans l'étude du Texas, comme du Nouveau-Mexique, des efforts (et donc des archives) du centre - Mexico - pour bâtir un État-nation véritable ${ }^{2}$, n'est pas assez visible dans l'ouvrage, tout au long duquel la focale, malgré les affirmations un peu rapides, demeure trop centrée sur San Antonio seule.

4 La démonstration d'une identité ethnique mexicaine en formation tout au long d'un parcours politiquement heurté n'est pas toujours d'une grande clarté. On a l'impression que passées les premières décennies, durant lesquelles une forme de collaboration, complexe, tortueuse parfois, est possible entre élites, l'indépendance texane, et plus encore l'intégration de l'État aux États-Unis, marque l'avènement d'une identité ethnique, voire raciale, imposée de l'extérieur, c'est-à-dire par les «Anglos » devenus majoritaires contre les Tejanos transformés en minorité sur leurs propres terres, dans leur propre ville, et que ce marquage sert à l'exclusion de tout un groupe de la gestion de la cité, voire de la "poursuite du bonheur ». Le schéma n'est pas neuf, les épisodes les plus fameux ayant déjà été traités par ailleurs ${ }^{3}$, mais l'ouvrage de Raúl A. Ramos a l'avantage d'offrir une synthèse claire et à jour de cette histoire.

\section{NOTES}

1. Deena J. Gonzalez, Refusing the Favor. The Spanish-Mexican Women of Santa Fe, 1820-1880, New York, Oxford University Press, 1999; Miroslava Chavez-Garcia, Negociating Conquest. Gender and Power in California, 1770s to 1880s, Tucson, University of Arizona Press, 2004 ; Maria 
Raquel Casas, Married to A Daughter of the Land. Spanish-Mexican Women and Interethnic Marriage in California, 1820-1880, Reno, University of Nevada Press, 2007.

2. . Andres Reséndez, Changing National Identities on the Frontier. Texas and New Mexico, 1800-1850, New York, Cambridge University Press, 2005.

3. . Paul D. Lack, The Texas Revolutionary Experience. A Political and Social History, College Station, Texas A\&M University Press, 1992; Andrés Tijerina, Tejanos and Texas Under the Mexican Flag, College Station, Texas A\&M University Press, 1994 ; Timothy M. Matovina, Tejano Religion and Ethnicity. San Antonio, 1821-1860, Austin, University of Texas Press, 1995 ; Gerald E. Poyo (ed.), Tejano Journey, 1770-1850, Austin, University of Texas Press, 1996. 